\title{
Analysis of constituents in different Fractions collected during distillation of Cardamom oil for flavour and fragrance applications
}

\author{
Biju K. Mani", Vinuthaa Murthy, Martin Boland, Kwang Yee \\ School of Psychological and Clinical Sciences, Charles Darwin University - Darwin, Australia.
}

\begin{tabular}{|c|c|}
\hline ARTICLE INFO & ABSTRACT \\
\hline $\begin{array}{l}\text { Article history: } \\
\text { Received on: } 18 / 05 / 2016 \\
\text { Revised on: } 11 / 08 / 2016 \\
\text { Accepted on: } 20 / 10 / 2016 \\
\text { Available online: } 31 / 01 / 2017\end{array}$ & $\begin{array}{l}\text { Cardamom oil is used widely for flavouring in food, as medicine, in aromatherapy and as a taste enhancer in } \\
\text { tobacco products as well as used in fragrance industry. Cardamom Oil is the essential oil of green cardamom } \\
\text { fruit produced by steam distillation from the seeds after they've undergone a long drying and de-husking } \\
\text { process. In the traditional distillation process, the oil collected on top of a separator half filled with water - as a } \\
\text { whole. The main components contributing to flavour and fragrance properties of cardamom oil are alpha-pinene, }\end{array}$ \\
\hline $\begin{array}{l}\text { Key words: } \\
\text { Cardamom, Cardamom Oil, } \\
\text { Essential oil, GC-MS, } \\
\text { Eucalyptol, } \\
\text { Gas Chromatograph, } \\
\text { Mass spectroscopy. }\end{array}$ & $\begin{array}{l}\text { distillation. These components are released from the seeds during distillation based on its volatility. This study } \\
\text { investigates the collection of cardamom oil in different fractions. Organoleptic as well as physical and chemical } \\
\text { analysis including Gas Chromatograph and Mass Spectroscope shows that there is a clear fractionation of the } \\
\text { components during distillation, which helps the end user to choose the right fraction based on what the } \\
\text { cardamom oil is used for. }\end{array}$ \\
\hline
\end{tabular}

\section{INTRODUCTION}

Essential oils have been known to mankind for many centuries. When the tomb of Egyptian Pharaos of the $20^{\text {th }}$ and $21^{\text {st }}$ dynasties were opened in 1881, the scent of Cymbopogan scheonantheus grass was easily detectable (Washwcton, 1906.) Oil of turpentine was well known to ancient Greeks. Almost 6000 years old traditional Indian system of medicine - Ayurveda, mentioned about distillation of spice oils in its recipes (Ajaikumar and Bharat, 2009). Today, this has developed into a large industry and many allied and value added industries have emerged from this ancient technology. (Bicchi and Sandra, 1987). Essential oils belong to the group of secondary metabolites from plants. Plants are metaphorically like a 'chemical factory', producing a wide range of complex compounds to promote growth and health (primary metabolites), some for defence and coexistence with the surrounding

* Corresponding Author

E-mail: bijumani @ hotmail.com eco-system (secondary metabolites) and some chemicals for reasons that are still unknown to science. Cardamom seeds and its essential oil or oil rich oleoresin are used widely for flavouring purpose in food, medicines, in aromatherapy and tobacco products as well as used in fragrance industry (Ajaikumar and Bharat, 2009). After saffron and vanilla, it is the third-most-expensive spice in the world (Winston, 2010).

It is the input to a range of products including food flavours, pharmaceutical goods (Joydeep et al., 2015), basic ingredient for most of the perfumes, aromatherapy and industrial solvents. As perfumers, flavour manufacturers and other end users prefer different 'notes' (descriptors of scents that can be sensed upon the application, measured as top-middle-base notes, which denote groups of scents/taste which can be sensed/taste with respect to the time after the application of a perfume/flavour) (Reinarz, 2014), these notes are created carefully with knowledge of the evaporation process and intended use of the perfumery/flavour ingredients of the essential oil components. If the essential oils can be collected as different fractions, these fractions can give specific notes at its end use. 
Table 1: Cardamom oil components (Ref. Parthasarathy et al., 2008).

\begin{tabular}{lclll}
\hline \multicolumn{2}{c}{ Main components } & & & \multicolumn{1}{c}{ Trace components } \\
\hline \multicolumn{1}{c}{ Components } & Total oil $\%$ & Hydrocarbons & Acids & Carbonyls \\
$\alpha$-Pinene & 1.5 & $\alpha$-Thujene & Acetic & 3-Methyl bultanal \\
$\beta$-Pinene & 0.2 & Camphene & Propionic & Butyric \\
Sabinene & 2.8 & $\alpha$-Terpinene & 2-Menthyl butyric & Pentanal \\
Myrcene & 1.6 & cis-Ocimene & 3-Menthyl butyric & -Acetoxy carvotanacetone \\
$\alpha$-Phellandrene & 0.2 & trans-Ocimene & Alcohols and Phenols & Cuminaldehyde \\
Llimonene & 11.6 & Toluene & 3-Menthyl butyric & Carvone \\
Eualyptol & 36.3 & $\rho$-Dimethylstyrene & $\rho$-Methyl-3-en-1-ol & Pinole \\
$\gamma$-Terpinene & 0.7 & Cyclosativene & Perillyl alcohol & $\alpha$-Terpinyl propionate \\
$\rho$-Cymene & 0.1 & $\alpha$-Copaene & Cuminyl alcohol & Dilhydro- $\alpha$-terpinyl acetate \\
Terpinolene & 0.5 & $\alpha$-Ylangene & $\rho$-Cresol & \\
Llinalool & 3 & $\gamma$-Cadinene & Thymol & \\
Linalyl acetate & 2.5 & $\Delta$-Cadinene & & \\
Terpinen-4-ol & 0.9 & & & \\
$\alpha$-Terpineol & 2.6 & & & \\
$\alpha$-Terpinyl acetate & 31.3 & & & \\
Citronellol & 0.3 & & & \\
Nerol & 0.5 & & & \\
Geraniol & 0.5 & & & \\
Methyl eugenol & 0.2 & & & \\
trans-Nerolidol & 2.7 & & & \\
\hline
\end{tabular}

Chemistry of the cardamom oil components is studied in detail by researchers (Kapoor et al., 2011, Khan, 2010, Leela, 2008 ) and from various locations (Parthasarathy et al., 2008) but no study is so far conducted for constituents in different fractions collected during distillation of cardamom oil for flavour and fragrance applications. Parthasarathy (Parthasarathy et al., 2008) summarised main components and trace components of Cardamom oil as shown in Table 1.

The basic tests and analysis required for quality assurance of an essential oil starts with organoleptic analysis followed by simple physical and chemical analysis like Specific gravity, optical rotation and polarity. Gas Chromatograph (GC) and Mass Spectroscopy are common and are considered as the most important tools to analyse the constituents of essential oils. Gas chromatography-mass spectrometry (GC-MS) can add further improvements to essential oil analysis where broad categories of monoterpenes and varying isomers closely resembling each other in terms of chemical structure can be individually identified (Chin et al., 2014). The GC-MS allows recognition of overlapping peaks on a GC by separating and identifying the constituents (Hunter, 2010).

A number of detectors can be used in chromatography and sensitivity has to be weighed off against the noise it produces. One of the most common is the flame ionization detector (FID), which is less sensitive than many specific detectors. FID detectors are mass rather than concentration sensitive and can detect most carbon containing substances, which makes them very suitable for the analysis of the majority of essential oils.

Raw materials for the study was tested and authenticated at Elixir Extracts, Kerala, India using analytical pharmacognosy tools (external morphology analysis, microscopy, volatile oil content, volatile oil analysis, alcohol soluble extractive, water soluble extractive, ash percentage and moisture content)

\section{MATERIALS AND METHODS}

\section{Production of essential oil of Cardamom}

A stainless steel steam distillation vessel is cleaned and steam sparged for 12 hours to ensure it is contamination free. Freshly crushed suitable quantity (approximately $75 \%$ of the distillation vessel by volume) Cardamom seed is loaded on a perforated stainless steel sheet and steam is passed from the bottom. Condensed vapour with liberated essential oil molecules travel through a condenser and finally collected on water. Temperature of the loaded material is noted every 5 minutes and controlled below $75^{\circ} \mathrm{C}$ for 2 hours. This first fraction is drained out after 2 hours, labelled and preserved. Second and third fractions are collected for the next 12 hours and 8 hours each at $80^{\circ} \mathrm{C}$ and $85^{\circ} \mathrm{C}$. The final fraction is collected for 4 hours or until the whole essential oil is liberated from the spent.

\section{Preservation and sample collection}

Anhydrous sodium sulphate is added to all the fractions immediately after collection $(0.05 \% \mathrm{w} / \mathrm{w})$ to remove moisture content. Sample is drawn to vials for analysis and sealed. Fractions are then transferred to air tight containers and kept in cool dry place under $25^{\circ} \mathrm{C}$.

\section{GC Analysis and confirmation using MS}

To determine the chemical composition of the essential oil in Cardamom, GC-MS is used. Initially, the essential oil fractions is analysed using a gas chromatograph (Agilent 7890A) 
equipped with an Agilent Flame Ionisation Detector (FID) and column (HP-5 5 \% Phenyl Methyl Siloxan: Agilent 19091J-413, HP-5 5\% Phenyl Methyl Siloxan, $325{ }^{\circ} \mathrm{C}: 30 \mathrm{~m}$ x $320 \mu \mathrm{m} \times 0.25$ $\mu \mathrm{m})$. The column is baked for 30 minutes at $280^{\circ} \mathrm{C}$ to minimise any chance of contamination and followed by oven programme method. Injection volume is $10 \mu \mathrm{l}$ split with a split ratio of 1:10 and injection temperature was $250^{\circ} \mathrm{C}$. The temperature programmed between 40 and $250{ }^{\circ} \mathrm{C}$ in the following way: $50{ }^{\circ} \mathrm{C}$ for $1 \mathrm{~min}, 50-185^{\circ} \mathrm{C}$ with $10{ }^{\circ} \mathrm{C} / \mathrm{min}$ and $230{ }^{\circ} \mathrm{C}$ for $1 \mathrm{~min}$.

The injections are repeated with a Gas Chromatograph coupled with Mass Spectroscope (Varian 431 integrated to Varian MS) using the same oven programme and flow properties. The auxiliary temperature is $230^{\circ} \mathrm{C}$ and the mass spectrometer (MS) is operating in EI mode $(70 \mathrm{eV})$ with a quadrupole temperature of $170{ }^{\circ} \mathrm{C}$. The data obtained is analysed using the Chemstation integration programme (Leela, 2008) together with a NIST02 mass spectra search library. In this study, for the GC-MS we have used is a 30mtr capillary column for essential oil analysis, which has been found to be very effective (Rajapakse et al., 1979) in analysis of volatiles with more than 150 ingredients.

\section{Organoleptic Analysis}

Smell, colour and taste are analysed using the traditional method. Smell strips are dipped in to the sample and air dried for 30 seconds and the smell is analysed. Colour is analysed against a light source and a small quantity is tasted and results noted. Solubility in water and alcohol (70\% alcohol v/v) and volatility are analysed at room temperature using distilled water and ethyl alcohol. Texture also is observed (by checking the sample in test tube with naked eye for clarity and by using finger tips to check greasiness).

\section{RESULTS AND DISCUSSION}

\section{Organoleptic Analysis}

Organoleptic evaluation of steam distilled cardamom oil fractions was done and the characters were studied and summarised in Table 2. The solubility of the fractions (in solvents such as water and alcohol), volatility, colour, smell and texture are studied. The oils from initial fractions are clear and colourless to yellow when extracted freshly whereas later fractions are light yellowish in colour, had strong aromatic and characteristic odour and bit greasy to touch. The oils are insoluble in water and soluble in organic solvents. All the fractions are lighter than water. These physical properties serve as a means of accessing the purity and quality of the volatile oils as well as their identification.

\section{Identification of key compounds}

The results obtained from the GC_MS were compared and the key compounds from each fraction were identified using overlay technique from the Chemstation32 software as well as NIST lib search of MS. The compounds identified in the 4 fractions are listed in Table 3. The GC chromatograms of all 4 fractions are shown in Figure1.

From GC analysis, of the first fraction, alpha-pinene has a retention time of $7.0 \mathrm{~min}$ and an area percentage of 71.5 and it is re confirmed using overlay and later with library in MS. Eucalyptol has a retention time of $13.04 \mathrm{~min}$ and an area percentage of 7.8. In the second fraction, area percentage of alphapinene is reduced to 42.64 at a retention time of 6.9 but area percentage of eucalyptol is increased to $37 \%$ at a retention time of $13.42 \mathrm{~min}$. MS analysis supported this findings. In the $3^{\text {rd }}$ fraction again the percentage of alpha pinene is further reduced to 1.35 at $6.9 \mathrm{~min}$ and the eucalyptol increased to $66 \%$ at $13.62 \mathrm{~min}$, which is again confirmed with MS analysis and data interpretation. Terpinyl acetate and geraniol occur at $15.5 \mathrm{~min}$ with approximately $2 \%$. In the fourth fraction (where higher temperature is applied to the extraction vessel to liberate the last traces of essential oils) apart from small amount of alpha pinene, eucalyptol, geraniol terpinyl acetate, linalool and nirolidol are also detected.

Quantity wise, alpha pinene, eucalyptol and $\alpha$-terpinyl acetate are the major components in the cardamom volatile oil that contribute to the basic cardamom aroma. The major chemical constituents that impart sweet flavour to the oil are $\alpha$-terpinyl acetate, geranyl acetate, nerol and $\alpha$-terpineol; while eucalyptol imparts harsh camphory note (Zachariah, Pillai et al 2008). We find the third fraction has highest level of eucalyptol. $\alpha$-terpinyl acetate content is recorded in $3^{\text {rd }}$ and $4^{\text {th }}$ fractions which has low alpha pinene content. Later fractions $\left(3^{\text {rd }}\right.$ and $\left.4^{\text {th }}\right)$ contain geranyl acetate, linalool and nerol when compared to other fractions.

Table 2: Organoleptic properties of fractions.

\begin{tabular}{|c|c|c|c|c|c|c|c|}
\hline 氖 & Smell & Colour & Taste & $\begin{array}{l}\text { Solubility } \\
\text { in Water }\end{array}$ & $\begin{array}{l}\text { Solubility } \\
\text { in Alcohol }\end{array}$ & Volatility & Texture \\
\hline 1 & pinous, leafy & colourless & characteristic cardamom & insoluble & soluble & highly volatile & less turbid, clear \\
\hline 2 & pinous, camphorous & colourless & characteristic cardamom & insoluble & soluble & medium volatile & less turbid, clear \\
\hline 3 & camphorous, fruity & colourless to light yellow & characteristic cardamom & insoluble & soluble & medium volatile & clear \\
\hline 4 & fruity, earthy & light yellow & characteristic cardamom & insoluble & soluble & volatile & Clear, slightly greasy \\
\hline
\end{tabular}


Table 3: Components of cardamom oil fractions with RT and area percentage.

\begin{tabular}{|c|c|c|c|}
\hline Fraction No & Compound & Retention Time (Min) & Percentage \\
\hline \multirow{2}{*}{1} & Alpha-pinene & 7.0 & 71.59 \\
\hline & Eucalyptol & 13.0 & 7.80 \\
\hline \multirow[t]{2}{*}{2} & Alpha-pinene & 6.9 & 42.64 \\
\hline & Eucalyptol & 13.42 & 37.21 \\
\hline \multirow[t]{4}{*}{3} & Alpha-pinene & 6.9 & 1.34 \\
\hline & Eucalyptol & 13.6 & 66.43 \\
\hline & Terpinyl acetate & 15.5 & 2 \\
\hline & Geraniol & 16.9 & 0.3 \\
\hline \multirow{6}{*}{4} & Alpha-pinene & 6.5 & 7.4 \\
\hline & Eucalyptol & 13.6 & 60.7 \\
\hline & Terpinyl acetate & 15.1 & 2.9 \\
\hline & Linalool & 15.5 & 1 \\
\hline & Geraniol & 15.7 & 4.3 \\
\hline & Nerolidol & 17 & 1.0 \\
\hline
\end{tabular}

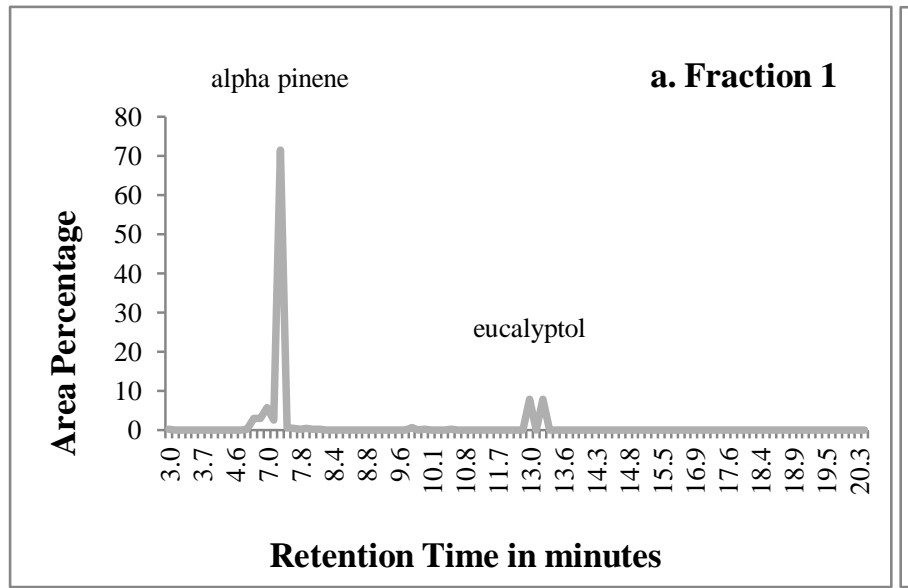

(a)

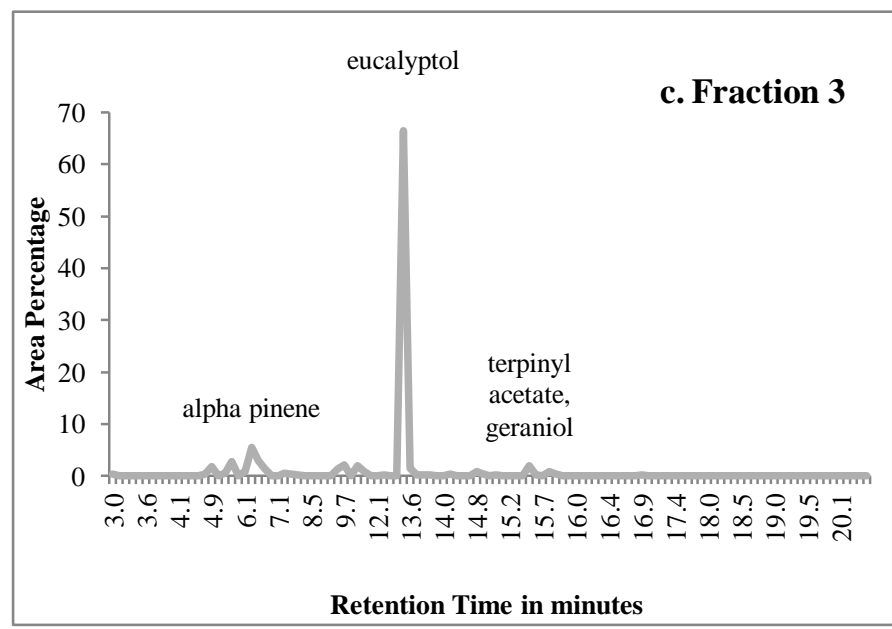

(c)

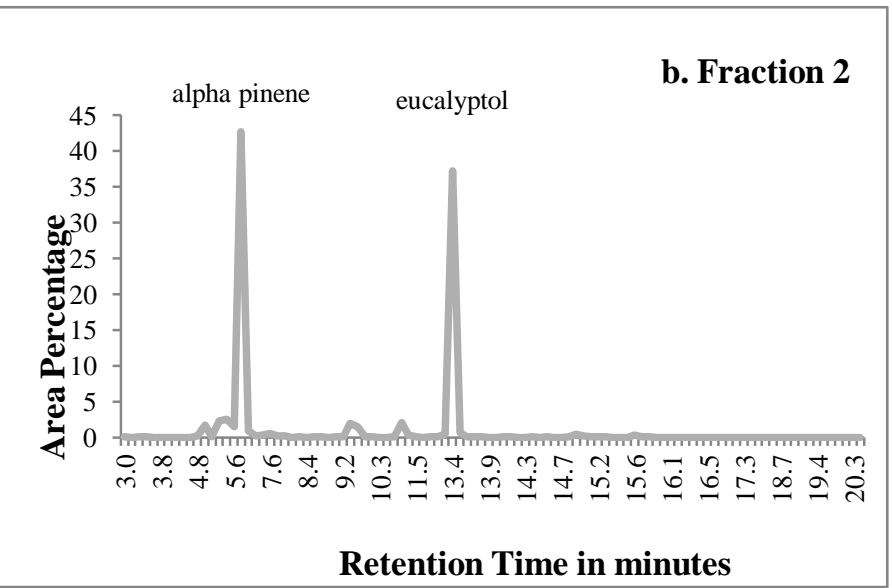

(b)

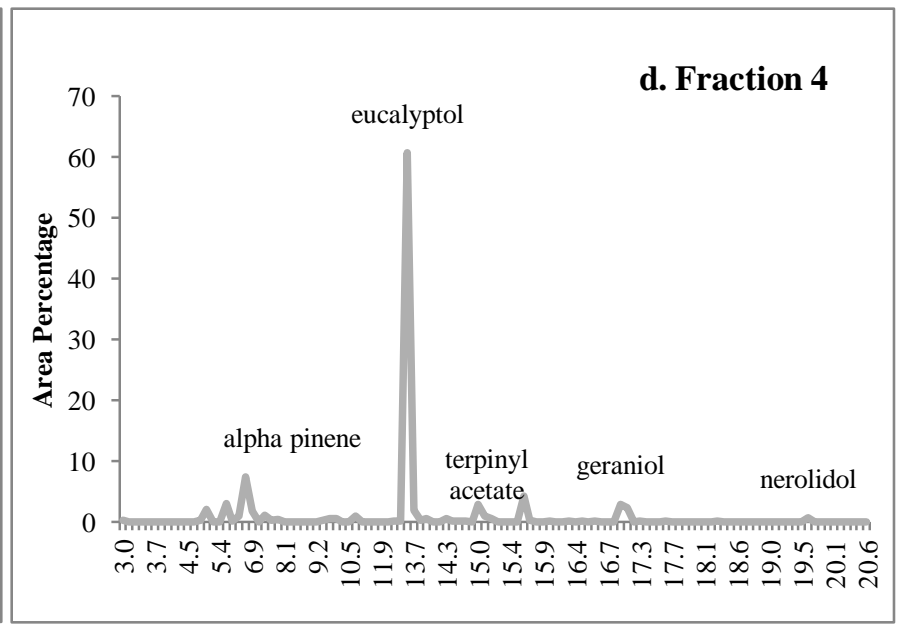

(d)

Fig. 1: Gas chromatogram of cardamom oil fractions. a) Fraction1, b) Fraction 2, c) Fraction 3, d) Fraction 4. 

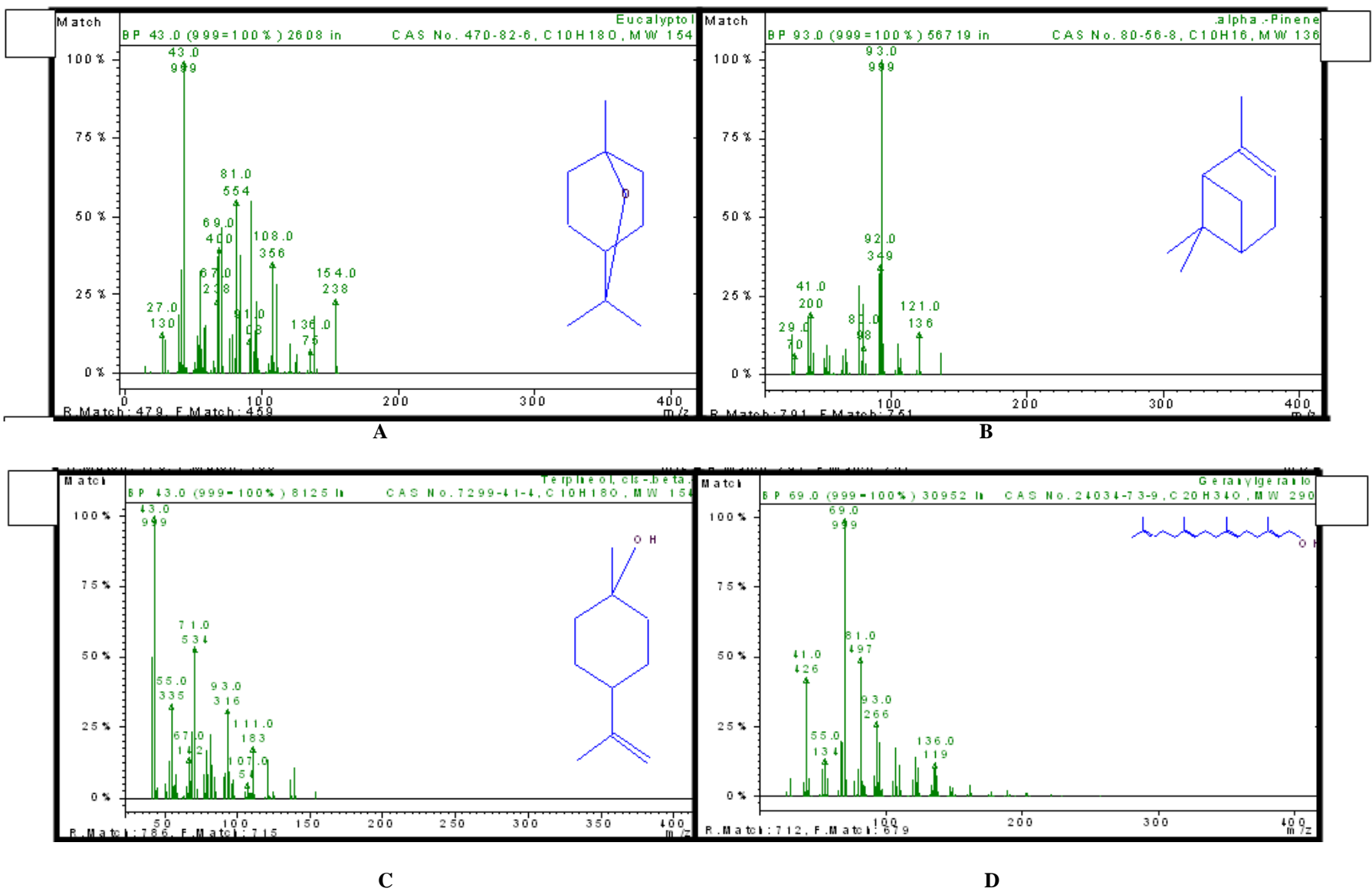

Fig. 2: Mass spectrograph of main compounds of cardamom oil: A - eucalyptol, B - alpha pinene, C - terpinyl acetate, D - geraniol.

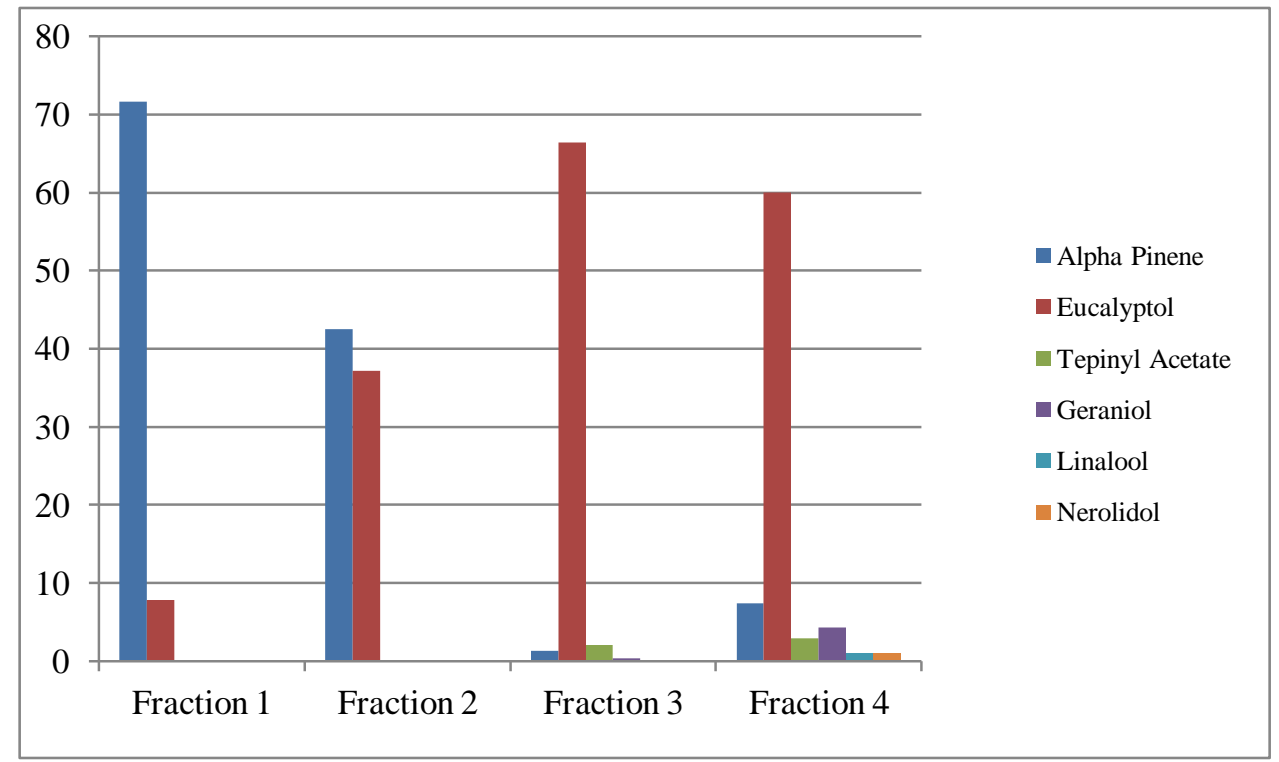

Fig. 3: Main ingredients of cardamom oil in each fraction. 


\section{CONCLUSION}

From the GC-MS analysis it can be clearly seen that the two main components are alpha-pinene and eucalyptol. The other chemical constituents that impart the cardamom flavour appear in fraction 3 and 4. There is a clear fractionation of the components during distillation, which helps the end user to choose the right fraction based on what the cardamom oil is used for.

Phenols and alcohols, the main constituent in the fourth fraction are defined as compounds having molecules with one or more hydroxy group bonded to a benzene ring. Compounds like nerols, linalool, and geraniols are defined as phenols or alcohols. These oxidise easily and are partly the reason why essential oils darken after distillation. Phenols and alcohols in cardamom oil also darken on exposure to air and tend to oxidate (Hunter and Murray 2010). As the colour is the one of the main factor determining essential oil quality, separating the essential oils into few fractions conserves the quality of the oils. Hence we can state that it is ideal to collect and store fractions separately. One of the main end use of Cardamom oil is food flavouring and it is the main constituent of majority of the flavours used in pastry, biscuit, cakes and a lot of Ready to Cook (RTC) and Ready to Eat (RTE) semi processed food products. Essential oils lose small quantities of volatile compounds when baked or even stored at high temperatures (Dima and Dima, 2015). Hence, when the final food is baked or heated, there is a higher chance of loss of the components of the first fraction as the boiling point and flash point is very low (Dima and Dima, 2015). The heat withstanding ability is much better for the $4^{\text {th }}$ fraction because it needs higher temperature to be released. Also, as the fourth fraction of the oil contains more phenols and alcohols and it tends to oxidise and change colour, it can be used to make oleoresins (a mixture of oil and resins) where colour is not a factor of quality or used in micro encapsulation (technique where each oil molecule can be coated with gum or modified starch) to prevent oxidation and also because it can withstand heat during cooking or baking

In perfumery and aromatherapy, the target temperature is very low (room temperature to body temperature) so it is ideal to use initial fractions (fraction 1or 2) of essential oil rather than the last fractions ( 3 or 4 ) to get good results.

This study emphasises the importance of separated collection of Cardamom oil into four fractions during steam distillation of cardamom seeds. Study proved the need of establishment of collection of the Cardamom essential oil into four fractions based on the GC fingerprint, which will benefit in the quality of essential oil based on its end use.

\section{Financial support and sponsorship: Nil.}

Conflict of Interests: There are no conflicts of interest.

\section{REFERENCES}

Ajaikumar BK, Bharat BA. 2009. Molecular Targets And Therapeutic Uses Of Spices: Modern Uses For Ancient Medicine, Gb, World Scientific Pub Co Pte.
Barnes J, Anderson LA,Phillipson JD. 2007. Herbal Medicines, London And Chicago, Pharmaceutical Press.

Bauer K, Garbe D,Surburg H. 1990. Common Fragrance And Flavor Materials: Preparation, Properties, And Uses, Weinheim, Federal Republic Of Germany, Vch Verlagsgesellschaft.

Buckle J. Use Of Aromatherapy As A Complementary Treatment For Chronic Pain. Alternative Therapies In Health And Medicine, 1999; 5, 42.

Burfield T. The Adulteration Of Essential Oils - And The Consequences To Aromatherapy \& Natural Perfumery Practice. Paper Presented To The International Federation Of Aromatherapists Annual Agm London 2003.

Bicchi C, Sandra P. 1987. Capillary Gas Chromatography In Essential Oil Analysis. Heidelberg: Huethig.

Chin S T, Nolvachai Y, Marriott P. J. Enantiomeric Separation In Comprehensive Two-Dimensional Gas Chromatography With Accurate Mass Analysis. Chirality, 2014; 26: 747-753.

Dima C, Dima, S. Essential Oils In Foods: Extraction, Stabilization, And Toxicity. Current Opinion In Food Science, 2015; 5: 29-35.

Essential Oil Composition Of Selected Cardamom Genotypes At Different Maturity Levels NK. Leela, D Prasath, MN. Venugopal Indian J. Hort. 2008; 65(3): 366-369

Evans WC, Evans D, Trease GE. 2002. Trease And Evans' Pharmacognosy, New York, Wb Saunders.

HuangY, Lam S L, Ho SH. Bioactivities Of Essential Oil From Elletaria Cardamomum (L.) Maton. To Sitophilus Zeamais Motschulsky. Journal Of Stored Products Research, 2000; 36: 107117.

Hunt, Dienemann J, Norton HJ, Hartley W, Hudgens A, Stern T, Divine G. Aromatherapy As Treatment For Postoperative Nausea: A Randomized Trial. Anesthesia \& Analgesia, 2013; 117: 597-604.

Hunter M. 2010. Essential Oils: Art, Agriculture, Science, Industry And Entrepreneurship, Nova Science Publishers, Inc. Nova Scintific

Jiao J, Fu Y-J, Zu YG, Luo M, Wang W, Zhang L, Li J Enzy.me-Assisted Microwave Hydro-Distillation Essential Oil From Fructus Forsythia, Chemical Constituents, And Its Antimicrobial And Antioxidant Activities. Food Chemistry, 2012; 134, 235-243.

Joydeep M, Devender P, Rachna K. Evaluation Of Antacid Activity Of Microemulsion Formulation Of Blend Of Essential Oil. International Journal Of Pharmaceutical Sciences And Drug Research, 2015; 7, 163-167.

Kapoor IP, Singh B, Singh G. Essential Oil And Oleoresins Of Cardamom (Amomum Subulatum Roxb.) As Natural Food Preservatives For Sweet Orange (Citrus Sinensis) Juice, 2011; (Vol. 34, Pp. 1101-1113). Malden, Usa: Blackwell Publishing Inc.

Ila D, Asha A, Deborah LB, Supti S, Elizabeth W, Eva P, Archana S, Sudin B,Tapas S. Antioxidative Effects Of The Spice Cardamom Against Non-Melanoma Skin Cancer By Modulating Nuclear Factor Erythroid-2-Related Factor 2 And Nf-[Kappa]B Signalling Pathways. The British Journal Of Nutrition,2012; 108, 984.

Murugan M, ShettyPK, Ravi, Anandhi A, Rajkumar AJ. Climate Change And Crop Yields In The Indian Cardamom Hills, 1978-2007 Ce. Climatic Change, 2012; 110(3), 737-753. Doi: 10.1007/S10584-011-0115-8

Leela NK, Amma DMNV. Essential Oil Composition Of Selected Cardamom Genotypes At Different Maturity Levels.2008; Indian J. Hort. 2008; 65(3): 366-369.

Plant Extracts: Role In Agriculture, Health Effects And Medicinal Applications, 2013. Nova Science Publishers, Inc.

Parthasarathy V A, Chempaka B, Zachariah TJ. 2008. Chemistry Of Spices. Gb: Cabi Publishing. 
Rajapakse-Arambewela LS, Wijesekera RO. G.L.C. Study Of The Essential Oil Of Wild Cardamom Oil Of Sri Lanka. Journal of The Science Of Food And Agriculture, 1971; 30(5), 521-527. Doi: 10.1002/Jsfa.2740300513

Reinarz J. 2014. Past Scents: Historical Perspectives On Smell. Champaign: University Of Illinois Press.

Washwcton M. 1906. Royal Botanic Gardens, Bulletin Of Miscellaneous Information.

Winston JC. 2010. Cardamom: The Queen Of Spices. Hagerstown MD USA. Vibrant Life USA.

\section{How to cite this article:}

Mani BK, Murthy V, Boland M, Yee K. Analysis of constituents in different Fractions collected during distillation of Cardamom oil for flavour and fragrance applications. J App Pharm Sci, 2017; 7 (01): 177-183. 